Cite as: Jones, K. and Morgan, C., (2001), Research in Mathematics Education: some issues and some emerging influences. In: Candia Morgan and Keith Jones (Eds), Research in Mathematics Education, volume 3. London: British Society for Research into Learning Mathematics, pp1-20. ISBN: 0953849813

\title{
RESEARCH IN MATHEMATICS EDUCATION: SOME RESULTS AND SOME EMERGING INFLUENCES
}

Keith Jones, University of Southampton

Candia Morgan, Institute of Education, University of London

Research carried out by members of the British Society for Research in Mathematics Education (BSRLM) is not only grounded in knowledge of developments in the field and of mathematics classrooms and other sites where mathematics teaching and learning occurs, but is also influenced by developments in education generally (in both practice and policy) and in closely related fields such as psychology and sociology, as well as mathematics itself. Recent research, such as that contained in this volume of BSRLM research papers, has been undertaken against a backdrop of severe criticism of the quality of education research in general, although little of this criticism appears to have been especially directed at mathematics education research. Nevertheless, emerging UK and international developments, some a direct consequence of the general criticisms of educational research, are likely to have a considerable impact on educational research in general, and on research in mathematics education in particular, in the coming years.

The purpose of this chapter is to introduce the papers in this collection of extended research reports from BSRLM [1]. We do that by first reviewing the general criticisms of educational research, looking briefly at the (possible) relationships between research, policy and practice. We then locate this collection of research papers in relation to some of these issues. As research in education is coming under increasing scrutiny it is appropriate to consider the likely impact of emerging research policy developments. These are considered in the second part of this chapter

\section{USES AND ABUSES OF EDUCATIONAL RESEARCH}

Users of educational research are, it is claimed, most interested in 'what works'. Griffin (2001), for instance, has observed that the types of 'products' of research in the social sciences that best meet the needs of policy makers are:

- those that provide answers;

- those that provide clear questions in the absence of clear answers;

- those that demonstrate a clear accumulation of findings over time;

- those that can be distilled to a single set of bullets.

Teachers, according to Desforges (2000), want the following from education research:

- standard and stable models of learning;

- coherent, organised, well-established findings;

- vibrant working examples of success; 
- research results converted as far as possible into the technologies of education into curriculum or other pedagogic materials.

Desforges argues that teachers "cannot work with models that change with the wind" and that they "do not have time for literature searches or for refined academic debates". He also suggests that, for teachers, "That something works is one thing. Examples of how it can be got to work are crucial.” (p.3, emphasis in the original)

Such observations indicate ways in which educational research is said be useful, providing, for example, evidence that can inform both policy and practice. Yet, as Edwards notes:

Recent calls for education policy and practice to be informed by evidence have been preceded and accompanied by strident complaints about the persistent failure of researchers to provide evidence worth using. (2000, p.3)

Such criticisms, which have been particularly prevalent in the UK, have come from politicians, policymakers and from within the research community itself. Examples include Hargreaves' (1996), assertion that educational research "is poor value for money in terms of improving the quality of education provided in school", and subsequent inquiries funded by the DfEE (Hillage, Pearson, Anderson and Tamkin, 1998) and Ofsted (Tooley and Darby, 1998), both of which were highly critical of educational research in general. A common feature of the criticisms contained in these reports has been their bluntness. Hargreaves, for example, is of the view that there is a considerable amount of

frankly second-rate educational research which does not make a serious contribution to fundamental theory or knowledge, which is irrelevant to practice; which is uncoordinated with any preceding or follow-up research; and which clutters up academic journals that virtually nobody reads. (1996, p.7)

The Ofsted-funded review of educational research by Tooley and Darby (1998) is similarly highly critical of educational research in general. Through an examination of a sample of 41 published educational research articles from four prominent journals, Tooley and Darby claim that a majority of educational research does not satisfy criteria of good practice. Most educational research, they declare, is partisan, poorly conducted, and irrelevant. They claim that "the picture emerged of researchers doing their research largely in a vacuum, unnoticed and unheeded by anyone else" (p.6). Even where education research does address policy-relevant and practical issues, Hillage et al. (1998) allege that it tends to be:

- small scale and incapable of generating findings that are reliable and generalisable;

- insufficiently based on existing knowledge and therefore capable of advancing understanding;

- presented in a form or medium which is largely inaccessible to a non-academic audience; and 
- lacking interpretation for a policy-making or practitioner audience.

Whatever the legitimacy of these general denunciations of educational research - and they have been rigorously contested (see, for example, Hammersley, 1997; Atkinson, 2000; but see Lagemann, 2000) - the strident criticisms noted above have led to a number of developments in the UK (some of which reflect developments taking place more widely) that will undoubtedly impact on the conduct of research in education in general, and in mathematics education in particular, over the coming years. These emerging developments are examined in the concluding parts of this chapter. For now we turn to the papers in this volume of research reports and examine them in the light of these criticisms of educational research.

\section{RESEARCH PAPERS FROM THE BRITISH SOCIETY FOR RESEARCH IN MATHEMATICS EDUCATION}

All the chapters in this volume originate from presentations at meetings of BSRLM during 1999, subsequently published as short papers in the proceedings of the Society. These papers were then substantially revised and expanded for consideration for this more formal publication. Each chapter was subject to blind peer review and only those judged to be of sufficient quality were accepted for publication. The review process, involving a group of experienced members of the Society with a wide range of expertise and interests, provided much constructive feedback, allowing authors to revise and strengthen their chapters. The Society has always sought to encourage and support new researchers as well as to provide a forum for those who are more experienced. This dual aim is reflected in the make-up of the group whose work comprises this volume. The authors range from well-established researchers with strong national and international reputations to new researchers, for whom the chapter included here may be their first refereed publication. They also include teachers of mathematics at various levels and research students as well as those involved in teaching and researching mathematics education in institutions of higher education.

This volume does not attempt to present a complete or representative overview of mathematics education research in Britain. Rather, it provides a snapshot of recent and current work. It displays interest in a broad range of issues in mathematics education, making use of different theoretical frameworks and methodologies and including both reports of empirical studies and more theoretical contributions. The chapters have been organised into four themes:

- Mathematics and schooling

- Teachers and teacher development

- Mathematics, language and meaning

- Technology and learning mathematics

Each of these themes is introduced at appropriate points in the volume. The purpose of this introductory chapter is not to describe them in any detail, nor to subject 
individual chapters to further critical review. Rather, the intention here is to frame the complete set of chapters against some of the issues raised above.

The first thing to observe is that the improvement of the experience of mathematics learners in all contexts is a central concern of each of the chapters in this volume. This applies whether the issue is the appropriateness of early experiences with number provided for young children (Godfrey and Aubrey), the need to make the human face of mathematical writing and mathematical activity more accessible to students at all levels (Morgan), the benefits of linking visual and algebraic ways of thinking in undergraduate mathematics (Chae and Tall), or the different kinds of knowledge that mathematics teacher educators need in order to enable trainee teachers of mathematics to acquire the requisite professional knowledge (Prestage and Perks). This focus on improving the experience of mathematics learners accords with the policy recommendation of the US National Educational Research Policy and Priorities Board that "the priority for research in education must be a high level of achievement for all students" (1999b, p.1), though various parties may well have their own views about what might constitute appropriate definitions of 'high achievement' and how this might be measured.

The concerns of the authors are also in many cases closely related to current priorities for teachers, curriculum developers and policy makers - priorities that may be driven by developments in education policy, by debates about the nature of the mathematics curriculum, by increased availability of new technologies. Thus we see chapters that engage with the teaching and learning of number (Foxman; Godfrey and Aubrey; Bills; Sutherland et al.) as the National Numeracy Strategy is introduced by the United Kingdom government. We have investigations into the teaching and learning of proof (Olivero) and algebra (Coles and Brown) - both of which have been identified as areas of weakness within the National Curriculum and in need of development (see Royal Society/JMC, 1996; 2001). National concern with the supply and quality of mathematics teachers and the nature of their induction into the profession is reflected in our choice of Teachers and teacher development as one of the four themes in this volume. Similarly, various aspects of the use of new technologies are addressed both in the chapters collected under the Technology and learning mathematics theme and elsewhere.

As noted above, Tooley and Darby (1998) generally commend research that builds on what is currently known and utilises a suitable theoretical framework. All the chapters in this volume locate themselves clearly in relation to existing research results and theory; however, 'building on what is known' is not a straightforward exercise. It may involve:

- taking account of results of previous studies when designing new research - as Godfrey and Aubrey have done in order to further illuminate our understanding of early mathematical development; 
- addressing questions that have been explicitly or implicitly raised by previous studies - as Smith does in studying the relationships between student teachers' expressed beliefs, their teaching approaches and their experiences during their training;

- extending the application of established theories and the investigation of recognised research issues into new areas of mathematics or different phases of education - as Chae and Tall have done in relation to visualisation and the development of conceptual understanding in the context of undergraduates studying the foundations of chaos theory;

- applying new theoretical insights or methodological tools to existing work - as Foxman has done in his re-analysis of data on mental calculation methods, originally studied in the 1980s;

- developing new theoretical perspectives with which to interrogate or explain previous results or commonly recognised phenomena - as Prestage and Perks and Crisan do in relation to teachers' professional knowledge;

- applying specific theoretical perspectives - as Williams et al. do in order to reconceptualise relationships between mathematics in school or college and in the workplace.

In other cases, however, researchers push the boundaries of our knowledge about mathematics education in rather different ways, including:

- investigating an issue that has previously been neglected - thus Sutherland et al. both make an initial contribution to our knowledge about primary mathematics text books and develop a framework for studying them;

- using close analysis of 'natural' or 'experimental' classroom data in order to test out, illustrate and develop theoretical perspectives on mathematics education thus Coles and Brown address teaching and learning algebra, Olivero investigates students' development of conjecturing and proving processes, and Elliott et al. look at the shared construction of meaning in group interaction;

- applying tools from other disciplines to develop new insights - thus Bills infers the nature of children's mental representations of numbers and operations from analysis of their spoken language, using metaphors and other tools from linguistics;

- challenging common assumptions and presenting alternatives - thus Morgan questions perceptions of the nature of mathematical writing, while Huckstep and Rowland argue for caution in invoking the notion of 'creativity' in justification for school mathematics.

The categorisation that we have offered above is, of course, only partial. Most of the chapters may be seen to draw on and build on existing research results, questions and theoretical perspectives in multiple ways. 
Given the range of concerns and purposes that we have already indicated, it is to be expected that the methodological approaches vary, since it is, of course, important that the research methods used match the research questions being pursued. Following the categorisation employed by Tooley and Darby (1998, pp.10-11), the majority of the chapters in this volume report studies involving the analysis of empirical data. Several of the chapters are more theoretical in intent, constructing philosophical theses or developing theoretical perspectives, informing their arguments with reference to previous empirical results or to well-chosen examples. The majority of the studies involving analysis of empirical data are what Hillage et al. (1998), somewhat disparagingly, call "small-scale", involving what are essentially case studies of single classes, small groups or small numbers of individual students, teachers or texts. Given the limited resources allocated to education research in general, and to mathematics education in particular, it is perhaps inevitable that much research is small-scale. Only two of the studies (Godfrey and Aubrey; Foxman) make use of more substantial data sets (and Foxman is working with data originally collected by the Assessment of Performance Unit nearly fifteen years ago). What is recognised, however, both by Tooley and Darby and by Hillage et al., is that it is not necessarily the size that matters (after all, only one counter-example is needed to disprove a mathematical theorem), but whether a study is capable of helping to generate findings that are reliable and generalisable.

Appropriateness of methodology and generalisability of findings were two important issues addressed by the reviewers of the chapters in this volume. In recommending acceptance for publication, the reviewers judged that the authors undertaking smallscale research were not making unwarranted generalisations but were pointing out how their paper could contribute to the development of more robust findings (something for which Tooley and Darby commend the only mathematics education research paper included in their random selection). Given the range of questions in each of the domains of mathematics education research identified by the CoPrIME/ BSRLM FRAME initiative (Mason, 2001), (discussed below and see Appendix 3), it is perhaps reasonable to conclude that, at the current level of funding, this represents a commendable achievement by these BSRLM researchers.

The purpose of this introductory chapter is not to subject the papers in this volume to the level of analysis undertaken by Tooley and Darby (1998). In their identification of themes such as partisanship (in terms, for instance, of the conduct and presentation of educational research), methodological weaknesses, and relevancy to practice, Tooley and Darby provide interested readers with possible means of engaging with the authors of the papers, or perhaps directly with the Executive Committee of BSRLM who oversee the production of volumes in this series. Certainly, the reviewers of individual papers, and the editors who oversaw the revision of the papers, paid special attention to the quality of the design, conduct and reporting of each research study published in this volume. 
Hopefully, the reader will find, if not answers, then clear questions that can help to lead to a clear accumulation of findings over time (even if these may not be able to be distilled to the single set of bullet points apparently beloved by policy makers). A particular feature of this collection is the focus on questions that are undoubtedly important to classroom practitioners. These include, for example, children's mental mathematics strategies (Foxman), the relationship between school-taught mathematics and that used in the workplace (William et al.), how mathematics teachers learn to use ICT in their teaching (Crisan), the relationship between trainee teachers' beliefs and their teaching approach (Smith), the possible impact on pupils' learning of representations in mathematics textbooks (Sutherland et al.), and the use of dynamic geometry software for conjecturing and proving in geometry (Olivero). While this collection of chapters may not provide teachers with everything they are looking for from research, it does contain working examples and, in some cases, findings that may contribute to the development and "warranting" (Ruthven, 1999) of suitable curriculum and other pedagogical materials and practices.

While considering the relevance of research to communities of users, it is necessary to address its accessibility (or inaccessibility) to members of these communities. The writing in this volume, arising as it does from meetings of BSRLM, is primarily addressed to an audience similar to that from which the membership of BSRLM is drawn. In other words, we expect the chapters to be most accessible to researchers and students in mathematics education and to those teachers, curriculum developers and policy makers who are already active readers and users of research. We hope that the writing is not unnecessarily obscure, but we recognise that it is not primarily addressed to practitioners. Having said this, many of the authors whose research is represented here also report their work directly to practitioners in professional journals such as Mathematics Teaching and Mathematics in School. Recently, abstracts of the research reported at BSRLM meetings have also started to be included in these journals. The joint FRAME initiative undertaken by CoPrIME and BSRLM (Mason, 2001) is similarly intended to address an audience of policy makers. By these means BSRLM is taking steps to widen the dissemination of the useful findings of research in mathematics education, to encourage dialogue between researchers, practitioners and policy makers and, by raising awareness of the activities of members of BSRLM, to widen participation in and with research among practitioners themselves.

While the research reported in this volume was undertaken against a backdrop of severe criticism of educational research in general, future research is going to be influenced by emerging trends in education research policy. The rest of this chapter reviews these emerging trends, beginning with a brief commentary on the current state (and status) of research in mathematics education. 


\section{THE STATE OF RESEARCH IN MATHEMATICS EDUCATION}

One positive indicator of the (good) quality of work in mathematics education comes from an unlikely source. As noted above, the Ofsted-funded review of educational research (Tooley and Darby, 1998) is highly critical of educational research in general, claiming that a majority of such research does not satisfy criteria of good practice. By chance, one of the articles analysed by Tooley and Darby is from the mathematics education community (the article is Coe and Ruthven, 1994). In their report, Tooley and Darby highlight the article as an example of good practice in methodology. Tooley and Darby note that in the Coe and Ruthven article:

Background ideas on the importance of proof in mathematics are clearly and comprehensively explored. The research is a small-scale qualitative study, but the authors do not make unwarranted generalisations from it. They treat it in the vein of a pilot study, pointing out how the methodology could be used for a larger study from which generalisations could be made. (1998, p.47)

Further evidence of the status of research in mathematics education comes from the assessment of the quality of UK education research by Professor Michael Bassey, Executive Secretary of the British Educational Research Association (BERA) and not himself a mathematics educator. Writing in the Times Higher Education Supplement of Friday 4 December 1998, Bassey suggests that the following categories of UK education research are 'world class' quality:

- school improvement;

- cognitive acceleration in science education;

- mathematical education;

- formative assessment;

- school action research;

- gender awareness.

Another example of the importance of UK research in mathematics education is that BERA have included it in their recent initiative to provide a 'map' of educational research in the UK. A major part of this initiative has been a series of 13 national events, each covering a different aspect of educational research, leading to a series of monographs. One of these events surveyed UK research in mathematics education, focusing on the teaching and learning of number, and was organised in collaboration with BSRLM (see Brown and Askew, 2001).

Not only are there these positive signs of the quality of research in mathematics education in the UK, a substantial quantity is also published. One indication of the volume of UK research in mathematics education can be found in the analysis of educational research submitted for the 1996 research assessment exercise (RAE) (Kerr, 1998). A major component of the RAE uses the details of the best four research publications published over the previous four years by each active UK researcher employed by a higher education institution. The approach adopted in 
Kerr's analysis of educational research was to identify key themes in the research and to map the concentration of research effort within and across those themes. Publications could be counted in more than one category. This approach found the largest number of publications to be in education policy (47\% of all papers), with 'subject-based enquiry' second (31.1\% of all papers). Of the 3115 papers classified as 'subject-based enquiry', the first three categories were:

Science education $\quad 513$

Mathematics education 419

English education $\quad 268$

This suggests that mathematics education is the second largest area of subject-based research in curriculum areas in the UK.

While there are thus some positive signs about research in mathematics education, we have to look to the future and, in particular, at emerging policy developments that are likely to impact on such work. These are examined in the final sections of this chapter.

\section{SOME DEVELOPMENTS IN POLICY ON EDUCATIONAL RESEARCH}

Significant recent developments in policy on educational research include:

- The establishment in the UK in September 1999 of a National Education Research Forum (NERF) and the beginnings of the development of a national education research framework (see http://www.nerf-uk.org/).

- The establishment internationally in 1999 of the 'Campbell Collaboration', an emerging international effort that aims "to help people make well-informed decisions by preparing, maintaining, and promoting access to systematic reviews of studies on the effects of social and educational policies and practices" (see http://campbell.gse.upenn.edu/).

While each of these developments is treated in more detail in Appendices 1 and 2 respectively, it is worth noting here that the main aim of NERF is to "develop a strategy for educational research, shape its direction, guide the coordination of its support and conduct, and promote its practical application”. To some extent, this mirrors similar developments in other countries. In the USA, for example, a National Educational Research Policy and Priorities Board (NERPPB) was established in 1994 "to forge a national consensus with respect to a long-term agenda for educational research, development, dissemination (NERPPB 1999a). The NERPPB also recognises that such research requires funding, arguing that "funding for educational research must be increased dramatically" and giving an interim target of about \$1.5 billion annually.

The work of NERF has not yet reached the level of detail of the NERPPB. It has neither established specific priorities for educational research, nor explicitly stated that an increase in funding for educational research, from what it identifies as less 
than $0.5 \%$ of the total national expenditure on education, is required in the UK. Yet developments internationally, described in more detail in Appendix 2 but summarised below, may well have a major impact on its work.

A particularly pertinent international development is the Campbell Collaboration. This enterprise intends to be a "multi-national collaboration" producing "systematic reviews" of which innovations in education (and in the social and behavioural sectors more widely) "work and fail". The Campbell Collaboration has already formed an Education Co-ordinating Group [2], produced draft review protocols (ways of generating reviews) and appointed lead reviewers for reviews of truancy programs, voluntary tutoring, peer assisted learning, and second language training. Its latest report (Campbell Collaboration Secretariat, 2001) indicates that negotiations have been undertaken to determine the feasibility of reviews on teacher induction and mentoring and on monetary incentives and educational achievement. In addition, lead persons have been identified for developing review protocols in mathematics learning, science learning, work-related learning and transferable skills, medical education, leadership and management in education, and assessment and learning.

In terms of mathematics learning the Campbell Collaboration "Organisational Framework for Preparing and Maintaining Systematic Reviews in Education" (see Davies, Wolf and Holmes, 2001) so far identifies some eight key papers in mathematics education research; the oldest being Hartley's meta-analysis of the effects of individually-paced instruction in mathematics (Hartley, 1977), and the most recent being Hembree's meta-analysis of the nature, effects, and relief of mathematics anxiety (Hembree, 1990). At the time of writing, the Education Coordinating Group is seeking a lead person for the mathematics and science reviews, although some preparation work has been done (see Leow and Boruch, 2001).

While these two developments (NERF and the Campbell Collaboration) have yet to have a major impact on UK research in mathematics education, the need to review what is known through research, reflected in such developments, has not gone unnoticed in the international mathematics education research community. This has already led to some developments in policy on research in mathematics education.

\section{DEVELOPMENTS IN POLICY ON RESEARCH IN MATHEMATICS EDUCATION}

The 1990s can be characterised as a time when research in mathematics education began to take stock. Examples of substantial efforts to review and define the field include the NCTM's handbook of research in mathematics education (Grouws, 1992), the ICMI study of the nature and results of mathematics education research in 1994 (and the resulting two volumes published subsequently, see Sierpinska and Kilpatrick, 1998), and encyclopaedias from publishers including Kluwer (Bishop, Clements, Keitel, Kilpatrick and Laborde, 1996), Routledge/Falmer (Grinstein and Lipsey, 2001), and, shortly, LEA (English, Bartolini Bussi, Jones, Lesh and Tirosh, in 
preparation). A review of research published in the BSRLM proceedings is currently underway (Nickson, in preparation).

Published reviews of these efforts to variously summarise and evaluate the considerable amount of research in mathematics education have generally been favourable. Nevertheless, not all found that these publications placed mathematics education research in a positive light. For example Steen (1999, p236), a prominent mathematics educator, thought that the ICMI study volumes "document a field in disarray, a field whose high hopes for a science of education have been overwhelmed by complexity and drowned in a sea of competing theories". If this is the case then it seems that further efforts by the mathematics education community would appear to be needed to achieve what Lagermann (2000, p. ix) calls "a high degree of internal coherence” necessary for sustained progress.

In the UK, some effort in this direction can perhaps be seen in the ongoing project initiated by the Committee of Professors in Mathematics Education (CoPrIME) and BSRLM and entitled the Formulation of a Research Agenda in Mathematics Education (FRAME) (see Mason, 2001). As a result of the work done so far on this initiative, the framework consists of nine domains of research (see Appendix 3), which represent a distillation of issues that CoPrIME and BSRLM have identified. Each domain of enquiry attempts to capture what the authors believe "need to be researched carefully in order to provide evidence which can inform both policy and practice”. An extended account of domain 5, on Mathematics Teachers' Professional Education and Development, is shortly to be published by BSRLM (see McNamara, Jaworski, Rowland, Hodgen, Prestage and Brown, in preparation)

This CoPrIME/BSRLM initiative demonstrates that the accumulation of evidence from research in mathematics education has made it possible to identify clear questions that warrant further research. The next section considers emerging influences on how such research may be carried out.

\section{EMERGING DIRECTIONS FOR THE FORM OF EDUCATION RESEARCH}

Towards the end of their review of the evidence base for what they call effective teaching, Muijs and Reynolds comment that, "there are robust findings on the learning and teaching of reading and literacy, and an increasingly strong research base of findings on the learning and teaching of mathematics (although this research base remains less strong than that on teaching literacy)" (2001, p.211). Precisely what Muijs and Reynolds mean by 'robust' is never made entirely clear but it may be assumed to be about how valid, reliable and generalisable research results are. It seems likely to be particularly concerned with the research design, including the use of comparison groups, representative samples, and the degree of replication (so that the intervention can be judged in various contexts).

Generalisable results tend to come from accumulated evidence from a series of smaller-scale projects, exemplified in the research presented in this volume, or from 
very large-scale projects. As Tooley and Darby (1998) observe (without seeming to notice that it is related to their criticism of the preponderance of small-scale research) there has been, and is, insufficient large-scale research in education in the UK.

While NERF has yet to say much if anything about the relative merits of funding many small project against funding a smaller number of larger projects (assuming a fixed level of funding), one current example of funding a few large-scale projects is the ESRC teaching and learning research programme. Despite a budget of $£ 23$ million, the objectives of the Programme are extraordinarily ambitious and include "enhancing the achievement of learners at all ages and stages in education, training and life-long learning" (see http://www.ex.ac.uk/ESRC-TLRP/). Of the four Research Networks funded in phase 1 of this initiative, and the nine Research Projects being funded under Phase II, there is only one that makes explicit reference in its title to an aspect of mathematics education (The Role of Awareness in the Teaching and Learning of Literacy and Numeracy in Key Stage 2 directed by Terezinha Nunes, Peter Bryant and Jane Hurry) although it is likely that other TLRP projects have mathematics education elements.

This brings the choice into sharp relief. If funding for educational research in the UK is not raised to a level comparable with that in the USA (where research grants of over a $\$ 1$ million are not unusual) the education community in the UK will have to continue to rely on the accumulation of evidence from smaller-scale studies or make do with a far smaller number of relatively large-scale studies.

While funding considerations may well move towards funding a relatively small number of reasonably large-scale studies, there are some strong forces coming to bear on the form this research may take. For example, the Campbell Collaboration Education Co-ordinating Group, in its plan to publish ten to fifteen systematic reviews each year (Campbell Collaboration Secretariat, 2001), is to focus almost exclusively on the results of research that employs a randomised control trial methodology (together with the use of previously published systematic reviews and meta-analyses such as those noted above by Hartley, 1977, and Hembree, 1990). According to the current Campbell Collaboration Secretariat report, the Campbell Controlled Trials Register (C2-SPECTR) already has over 10000 entries covering Social, Psychological, Educational, and Criminological research.

Another example is the review by Dixon, Carmine, Lee and Wallin (1998) of what they call "high quality experimental mathematics [education] research". In this somewhat contested review (see, for example, Kilpatrick, 1999; Becker and Jacob, 2000), the authors argued that of some 8727 studies in mathematics education published since 1970, only 956 articles satisfied "minimum identification criterion of being an experimental study of mathematics" (p.3). Furthermore, of the 956 studies, only 110 met further criteria (to do with an interpretation of various aspects of validity) imposed by the Dixon et al. In the end, the review consisted of the findings from just these 110 studies. 
While this is not the place to discuss in detail the contribution of randomised control trial (or experimental) methodology, it is worth noting that exclusive reliance on their use is not uncontested, even in medical research (see Howie, 2000, and also Pirrie, 2001). There is a danger that forms of knowledge that may be equally useful, gained by other methodologies, will be devalued and neglected. As Kilpatrick (1999) notes, in terms of research in education, this restriction to experimental studies, selected according to criteria such as those imposed by Dixon et al. or by the Campbell Collaboration, represents a common but unfortunate misunderstanding of educational research and the kind of knowledge it can contribute to efforts to improve teaching and learning. First, educational methods that people are interested in implementing do not have the specificity of medical treatments. Secondly, research cannot on its own decide what happens in places where mathematics teaching and learning occurs because it cannot be used to resolve matters that are really about values and priorities. Thirdly, teachers have a critical role in influencing how mathematics teaching and learning occurs. In medicine, drugs and therapies depend much less on the competence and attitude of the administering physician than teaching does on the competence and attitude of the teacher.

\section{CONCLUDING COMMENTS}

At the moment it appears that NERF has run out of steam. Apart from recently publishing an analysis of the responses they received to their consultation paper on 'Research and Development for Education' (NERF, 2001) NERF appears to have no specific objectives, targets or timeframe. How they will produce a national education research framework for UK educational research is anyone's guess. As their consultation response paper records "whilst the idea of some sort of framework for educational research gains support there is enormous reservation about the Forum and the strategy in terms of aims, scope and ability to deliver" (p.2).

NERF could do well to examine a recent analysis of the impact of educational research in Australia (particular educational research carried out in Australia) as the report claims to provide "compelling evidence that Australian educational research is respected internationally and makes a difference in the worlds of schools, and policy development” (Department of Education, Training and Youth Affairs, 2000, p.4). For example, a survey carried out for the inquiry found that "almost all the school principals, professional associations of educators, and school system administrators [sampled in Australia] expressed the view that educational research had benefited Australian education (p.5). In the UK, a recent paper by Galton (2000) reports evidence that teachers in the UK take the results of educational research seriously.

In the US, the NERPPB has, since 1994, undertaken systematic investigation on the dimensions and scope of educational research and development and, based on this work, has published a first comprehensive statement on research in education (see NERPPB 1999b). This document gives the first goal for education research as raising student achievement, stating that "the priority for research in education must be a 
high level of achievement for all students, and, within that domain, the initial emphasis should be on reading and mathematics achievement" (emphasis in original) (p.1). In mathematics, the document states, research is needed on "why students have so much trouble making transitions (e.g., from concrete objects to more abstract ideas), understanding formal representations, multiplicative reasoning, and essential mathematical and statistical concepts, such as chance, randomness, and probability”.

Perhaps NERF will take notice of this US report and of the CoPRIME/BSRLM initiative to develop a research agenda for UK research in mathematics education. Or perhaps UK involvement at Government level in the Campbell Collaboration, which is already high, will take things in another direction.

According to the Campbell Collaboration Secretariat report, Philip Davies, Co-chair of the Campbell Collaboration Education Coordinating Group is Deputy Director of Policy Evaluation and Policy Studies in the UK Cabinet Office (as well as professor in the Department for Continuing Education at the University of Oxford). In a presentation at the BERA conference in 1999, Judy Sebba, the main Campbell Collaboration contact at the UK Department for Education and Skills (DfES), explained UK Government thinking on developing evidence-informed policy and practice in education (Sebba, 1999). In her talk she offered her 'litmus test' for this initiative:

In ten years time a pupil will be able to access a website to find out the best way to be taught fractions. If the teacher is not using that method the pupil can ask why not.

This echoes both the 'consumer network' of the Cochrane collaboration (see Appendix 2), where anyone can get evidence to help them "make decisions about health care", and the people from NICE (The National Institute for Clinical Excellence), who provide "authoritative, robust and reliable guidance on current best practice". When asked, at her BERA presentation, what would happen if the teacher in her example was using a superior method to that given on the website, Judy Sebba appeared unable to provide an adequate response. While there are another eight years left to find out what will become of Sebba's litmus test, it does focus attention on just what are reasonable expectations of research in mathematics education.

\section{NOTES}

1. All the BSRLM papers referred to in this chapter appear in C. Morgan and K. Jones (eds), Research Papers in Mathematics Education, volume 3. London: BSRLM.

2. The Campbell Collaboration Education Group has a website but at the time of writing it has no content. See: http://aix1.uottawa.ca/ iupsys/campbell/education.html

All URLs quoted in this chapter were in operation when this chapter went to print (September 2001). 


\section{APPENDIX 1}

\section{THE UK NATIONAL EDUCATION RESEARCH FORUM (NERF)}

Following its establishment in 1999, the first task NERF has undertaken has been to produce discussion documents (available from NERF) on each of the following:

- identifying priorities for educational research;

- the quality of educational research;

- building research capacity;

- research funding;

- the impact of research on policy and practice.

The key recommendations in these discussion documents are:

- investment in an ongoing horizon-scanning exercise, designed and executed specifically for education as a method of identifying educational research priorities;

- that, within its own terms, any particular research study or project should be of good quality with respect to those terms;

- a systematic appraisal of the current state of research capacity - perhaps initially through a consultation process informed by a commissioned review drawing together and supplementing existing reports, but eventually through the maintenance of a 'register' of capacity;

- the establishment of a funders' group to enable funders of educational research to share thinking about priorities and to exchange information about practices;

- the development of a model of educational research and the place of impact describing the means by which research can have a warranted impact on policy and practice.

In addition to the establishment of NERF, several research centres have been have been set up: the Centre for Economics of Education, the Centre for ICT in Education, The Wider Benefits of Learning Research Centre, and the Evidence for Policy and Practice Information and Co-ordinating Centre (EPPI-Centre).

Alongside these developments are continuing efforts to involve teachers in schools in research (through Government initiatives such as 'Professional Bursaries', 'Best Practice Research Scholarships', and research opportunities through the Teachers' International Professional Development programme). In addition, a database called Current Educational Research in the UK (CERUK,) and maintained by the National Foundation for Educational Research (NFER), has been established to record all UK educational research at $\mathrm{PhD}$ level and above. The main UK funding body for educational research, the Economic and Social Research Council (ESRC) has also set up an Evidence-Based Policy and Practice Network (not restricted to education) to "improve the capacity for exchange of research-based evidence between public policy researchers and practitioners and to contribute to the improvement of quality of research, policy development and practice” (see http://www.evidencenetwork. org/). 


\section{APPENDIX 2}

\section{THE CAMPBELL COLLABORATION}

The Campbell Collaboration, established in 1999, is named after the American psychologist Donald Campbell (1917 -1996) who consistently drew attention to what he saw as the need to assess more rigorously the effects of research efforts, especially in the social sciences. Boruch, Petrosino and Chalmers (1999) provide three reasons for establishing the organisation: (a) a surge of interest in high-quality evidence for public policy decisions, (b) the increased frequency in using randomised field trials to discern the effects of new programs or new variations on existing programs, and (c) the increased frequency of systematic reviews.

The precedent for the Campbell Collaboration is the Cochrane Collaboration in health care (see http://www.cochrane.org), which was established in 1993. The Cochrane Collaboration has, to date, produced over 1000 systematic reviews of studies of health-related interventions, and has over 800 further reviews in preparation. They have a 'consumer network' (see http://www.cochraneconsumer.com) where anyone can get summaries of Cochrane reviews of evidence to help them "make decisions about health care". In a related development in the UK, NICE - The National Institute for Clinical Excellence - was set up as a Special Health Authority for England and Wales on 1 April 1999. It is part of the National Health Service (NHS), and its role is to provide patients, health professionals and the public with "authoritative, robust and reliable guidance on current best practice" (see http://www.nice.org.uk). The Campbell Collaboration aims to build on the experience of the Cochrane Collaboration and, presumably, develop the same form of products.

\section{APPENDIX 3}

\section{COPRIME/BSRLM FORMULATION OF A RESEARCH AGENDA IN MATHEMATICS EDUCATION (FRAME)}

Currently, the framework consists of nine domains of research (see Mason, 2001).

\section{Domain 1: Curriculum Design and Implications}

Who decides the intended mathematics curriculum, and what are their intentions? How do these intentions manifest themselves in the curriculum as planned, as taught, and as experienced by children? What is the background philosophy and what are the underlying assumptions being made by the current National Curriculum and the National Numeracy Strategy? Given the form and format of the National Curriculum and the National Numeracy Strategy, what perception of mathematics and of mathematics education (teaching and learning) is being promulgated as a result? What are the social and educational implications of this perception? 


\section{Domain 2: Digital technologies}

What epistemological and pedagogical criteria drive the design and use of digital technology in support of mathematics education? What are the implications of restricted access to technology through policy and through economic inequities, as experienced both here and abroad?

\section{Domain 3: Levels}

What are the criteria which determine achievement at level 4 in the mathematics National Curriculum? Are these criteria adequately tested by current tests? Are the test results robust against changes in time of year, changes in questions, and are they robust over time? How are the criteria themselves changing over time? Do they really represent what we want pupils to achieve?

\section{Domain 4: Mathematical Topics and Themes}

In order to inform teacher practices in specific topics, we need to know a great deal more about the struggles and difficulties which pupils experience when teachers use specific approaches in specific topics in mathematics.

\section{Domain 5: Professional development}

Numerous training programmes for mathematics teachers are in operation, or have been recently, with many variants (different ITE routes, 20 day courses, lead teachers, ICT training for all teachers, NNS cascade training, needs assessment for KS2, updating of teachers at KS3, Thinking Skills, ...). What impact are these having on their intended audiences, and is there visible evidence of positive change in pupils' experience as a result?

\section{Domain 6: Preserving Strengths}

Is the weakened emphasis on practical work and problem solving aspects in the current national policy in mathematics building on strengths, and is it having an effect on pupils' performance on TIMMS-like tests? How would a sample of UK students score now?

\section{Domain 7: Mathematics in the Curriculum}

What aspects of mathematics and of mathematical thinking are essential for full participation in a democratic society? What are the different trajectories of children coming from different backgrounds (socio-economic, gender, ethnic origin, ...) through public examinations and tests in mathematics, and through post-compulsory education?

\section{Domain 8: Top-Down and Bottom-Up}

How is it possible to balance standardised curricula with individual needs and differences? How can a teacher of thirty or more pupils in each lesson address individual needs, and how do national policies and espoused practices support teachers in this? 


\section{Domain 9: How Mathematics is Perceived}

Is there evidence that attitudes and beliefs about mathematics are becoming more positive as a result of current initiatives? Is mathematics seen by pupils as opening up their future options?

\section{REFERENCES}

Atkinson, E.: 2000, 'In defence of ideas, or why 'What works' is not enough.' British Journal of the Sociology of Education, 21(3), 317-330.

Becker, J. and Jacob, B.: 2000, 'The politics of California school mathematics: the anti-reform of 1997-99.’ Phi Delta Kappan, 81(7), 529-537.

Bishop, A. J., Clements, K. Keitel, C. Kilpatrick, J. and Laborde, C. (eds.): 1996, International Handbook of Mathematics Education. Dordrecht: Kluwer Academic.

Boruch, R., Petrosino, A. and Chalmers, I.: 1999, The Campbell Collaboration: a proposal for systematic, multi-national, and continuous reviews of evidence. Background paper for the meeting at The School of Public Policy, University College London, 15/16 July 1999.

Brown, M and Askew, M.: 2001, Teaching and Learning Numeracy: Policy, Practice and Effectiveness. Nottingham: BERA/BSRLM.

Campbell Collaboration Secretariat: 2001, The Campbell Collaboration: Concept, Status, and Plans. Philadelphia PA: Campbell Collaboration.

Coe, R. and Ruthven, K.: 1994, 'Proof practices and constructs of advanced mathematics students.' British Educational Research Journal, 20(1), 41-53.

Davies, D. Wolf, F. M. and Holmes, L.: 2001, An Organisational Framework for Preparing and Maintaining Systematic Reviews in Education: A Discussion Document. University of Pennsylvania, Philadelphia PA: Campbell Collaboration Secretariat.

Department of Education, Training and Youth Affairs: 2000, The Impact of Educational Research. Canberra, ACT: DETYA.

Desforges, C. W.: 2000, Familiar Challenges and New Approaches: necessary advances in theory and methods in research on teaching and learning. The Desmond Nuttall/Carfax Memorial Lecture, BERA, Cardiff, 2000.

Dixon, R. C., Carnine, D. W., Lee, D.-S., and Wallin, J.: 1998, Review of High Quality Experimental Mathematics [Education] Research: Report to the California State Board of Education and addendum to principal report. Eugene: University of Oregon, National Center to Improve the Tools of Educators.

Edwards, T.: 2000, Some Reasonable Expectations of Educational Research. UCET Research Paper No 2.

English, L., Bartolini Bussi, M. G., Jones, G., Lesh, R., and Tirosh, D. (eds.) (in preparation), Handbook of International Research in Mathematics Education. Mahwah, NJ: Lawrence Erbaum Associates. 
Galton, M.: 2000, Integrating Theory and Practice: Teachers' Perspectives on Educational Research. Paper presented at the Teaching and Learning Research Programme Conference, 9 -10 November 2000, Leicester.

Griffin, J.: 2001, Who Are the Users? Paper presented at The Campbell Collaboration First Annual Colloquium, February 2001, University of Pennsylvania, Philadelphia, PA.

Grinstein, L. S. and Lipsey, S. I. (eds.): 2001, Encyclopedia of Mathematics Education, New York: RoutledgeFalmer.

Grouws, D. A. (ed.): 1992, Handbook of Research on Mathematics Teaching and Learning. New York: Macmillan.

Hargreaves, D. H.: 1996, Teaching as a Research-based Profession: possibilities and prospects. The Teacher Training Agency Annual Lecture 1996.

Hartley, S. S.: 1977, Meta-analysis of Effects of Individually Paced Instruction in Mathematics. Doctoral Dissertation, University of Colorado.

Hammersley, M.: 1997, 'Educational research and teaching: a response to David Hargreaves’ TTA lecture.' British Educational Research Journal, 23(2), 141- 161.

Hembree, R.: 1990, 'The nature, effects, and relief of mathematics anxiety.' Journal for Research in Mathematics Education, 21, 33-46.

Hillage, J., Pearson, R., Anderson, A. and Tamkin, P.: 1998, Excellence in Research on Schools. The Institute of Employment Studies. London: DfEE Publications.

Howie, J. G. R.: 2000: 'Is it knowing or understanding that matters?' Medical Education, 34, 246-247.

Kerr, D.: 1998, Mapping Educational Research in England: An analysis of the 1996 Research Assessment Exercise. Bristol: National Foundation for Educational Research and the Higher Education Funding Council for England

Kilpatrick, J.: 1999; The Role of Research in Improving School Mathematics. Invited Address to the AMS-MAA-SIAM Joint Mathematics Meetings, San Antonio, Texas, January 13-16, 1999.

Lagemann, E. C.: 2000, An Elusive Science: The Troubling History of Education Research. Chicago: University of Chicago Press.

Leow, C. and Boruch, R. F.: 2001, Locating Randomized Experiments on Math and Science Education: A Hand Search and Machine-Based Searches of the American Educational Research Journal. University of Pennsylvania, Philadelphia PA: Campbell Collaboration Secretariat.

Mason, J.: 2001, FRAME: Formulating A Research Agenda for Mathematics Education. Milton Keynes: CoPrIME.

McNamara, O., Jaworski, J., Rowland, T., Hodgen, J., Prestage, S. and Brown, T.: in preparation, Mathematics Teaching and Teachers' Professional Education and Development: Formulating a Research Agenda for Mathematics Education. London: BSRLM. 
Muijs, R.D., Reynolds, D. (2001). Effective Teaching: Evidence and Practice. London: Paul Chapman Publishing.

National Educational Research Forum: 2001, Analysis of responses to 'Research and Development for Education: A national strategy consultation paper'. London: NERF.

National Educational Research Policy and Priorities Board: 1999a, The National Educational Research Policy and Priorities Board: Its Role, Development and Prospects. Washington, DC: NERPPB.

National Educational Research Policy and Priorities Board: 1999b, Investing in Learning: A Policy Statement with Recommendations on Research in Education by the National Educational Research Policy and Priorities Board, Washington, DC: NERPPB.

Nickson, M.: in preparation, A Review of BSRLM Research, 1995-2000. London: BSRLM.

Pirrie, A.: 2001, 'Evidence-based practice in education: the best medicine?' British Journal of Educational Studies, 49(2), 124-136.

Royal Society/JMC: 1996, Teaching and Learning Algebra pre-19. Report of a Royal Society/JMC working group chaired by Professor R. Sutherland. London: The Royal Society.

Royal Society/JMC: 2001, Teaching and Learning Geometry 11-19. Report of a Royal Society/JMC working group chaired by Professor A. Oldknow. London: The Royal Society.

Ruthven, K.: 1999. 'Reconstructing professional judgement in mathematics education: From good practice to warranted practice.' In C. Hoyles, C. Morgan \& G. Woodhouse (eds.), Rethinking the Mathematics Curriculum (pp. 203-216). London: Falmer.

Sebba, J.: 1999, Developing evidence-informed policy and practice in education. Paper presented at the British Educational Research Association Conference, University of Sussex, Brighton, 2-5 September, 1999.

Sierpinska, A. and Kilpatrick, J. (eds.): 1998, Mathematics Education as a Research Domain: A Search for Identity. Dordrecht: Kluwer

Steen, L.A.: 1999, 'Theories that gyre and gimble in the wabe.' Journal of Research in Mathematics Education, 30(2), 235-241.

Tooley, J. and Darby, D.: 1998, Educational Research: a critique. London: Office for Standards in Education. 